\title{
Optical and electrical properties of Si nanocrystals embedded in SiC matrix
}

\author{
Rimpy Shukla ${ }^{1,3,{ }^{*}}$, C. Summonte ${ }^{1}$, M. Canino ${ }^{1}$, M. Allegrezza ${ }^{1}$, M. Bellettato ${ }^{1}$, A. Desalvo ${ }^{2}$, D. Nobili ${ }^{1}$, S. \\ Mirabella ${ }^{2}$, N. Sharma ${ }^{3}$, M. Jangir ${ }^{3}$, I. P. Jain ${ }^{3}$ \\ ${ }^{1}$ CNR-IMM, via Gobetti 101-40129 Bologna, Italy \\ ${ }^{2}$ CNR-IMM, via Santa Sofia 64-95123 Catania, Italy \\ ${ }^{3}$ Centre for Non-Conventional Energy Resources, University of Rajasthan, Jaipur, India
}

*Corresponding author. Tel: (+39) 51-639-9136; Fax: (+39) 51-639-9216; E-mail: rimshu21@ gmail.com

Received: 12 May 2012, Revised: 28 May 2012, Accepted: 03 June 2012

\section{ABSTRACT}

Silicon nanocrystals ( $\mathrm{Si} \mathrm{NCs}$ ) embedded in a dielectric matrix showing tunable band gap properties have recently emerged as attracting top absorbers in silicon based high efficiency multijunction devices. This paper presents optical and electrical characterization of $\mathrm{Si} \mathrm{NCs}$ in $\mathrm{SiC}$ matrix resulting from annealing at $1100{ }^{\circ} \mathrm{C}$ of silicon-rich carbide (SRC)/SiC multilayers produced by Plasma Enhanced Chemical Vapour Deposition (PECVD), varying either the Si content in the SRC or the SiC thickness. Simulation of Reflectance and Transmittance spectra in the UV-Vis revealed that 1) the Si crystallization increases with increasing Si content; 2) a severe shrinkage of the multilayers occurs upon annealing due to the release of hydrogen and to crystallisation; 3) the growth of nanocrystals is affected by atomic environment and diffusivity of involved atoms at the investigated temperature. Temperature dependent conductivity measurements are performed on multlayers and on reference layers. The results show evidence of defect state conduction in the SiC matrix. Copyright (C) 2012 VBRI Press.

Keywords: Si nanodots; SiC; optical reflectance and transmittance; electrical conductance.

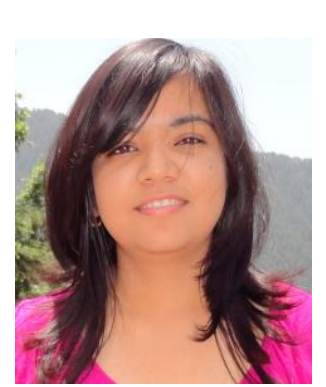

Rimpy Shukla is doing her Ph.D. in Physics under supervision of Prof. I.P. Jain from Centre for Non-Conventional Energy Resources (CNER) University of Rajasthan, Jaipur, India. She is working on Synthesis and Characterization of Silicon-Based Quantum Dot Solar Cells at CNR-IMM, Bologna, Italy. Previously she had done M.Phil. and M.Sc in Physics from the University of Rajasthan, Jaipur and University of Bikaner respectively.

\section{Introduction}

The possibility of obtaining band gap modulation in silicon nanodots in dielectric matrix, typically $\mathrm{SiO}_{2}$, has been proven since long [1]. The reduction of the silicon particle diameter to nanometric size produces the formation of minibands with consequent enlargement of the effective band gap [2]. The nanoparticles are formed by depositing a silicon rich material, and then inducing the precipitation of the excess silicon by thermal treatments. The control of the phenomenon is strictly subordinated to the control of the nanoparticle size, which is normally achieved using the multilayer approach [3-5] in the version of Zacharias [6] that proposes a procedure to separately control the density and size of nanocrystals. The approach consists of depositing multilayers with alternated stoichiometric and silicon rich composition. In this way, the nanoparticles only form in the silicon rich sublayer (=well layer), and the vertical size is controlled by the thickness of the sublayer itself.

Thanks to their quantum confinement capability, silicon nanocrystals, (nc-Si) are presently considered as a leading-edge material as tunable absorbers in the framework of photovoltaic applications, as in principle they allow to optimize the design of multijunction devices better matched to the solar spectrum [7]. For the embedding dielectric matrix, a trade-off between confining properties and acceptable conductivity is desired. Under this respect, the $\mathrm{SiC}$ matrix, among others (typically $\mathrm{SiO}_{2}$ or $\mathrm{Si}_{3} \mathrm{~N}_{4}$ ), is considered more promising, because of better conduction properties and lower barrier to $\mathrm{Si}$ nanoparticles [8]. However, unlike the case of $\mathrm{Si} / \mathrm{SiO}_{2}$ system, the $\mathrm{Si} / \mathrm{SiC}$ system is less investigated, mainly because of the less ideal properties, such as phase separation, that is less favoured in the case of $\mathrm{Si} / \mathrm{SiO}_{2}$, because the bond energy difference between $\mathrm{Si}-\mathrm{Si}$ and $\mathrm{Si}-\mathrm{C}$ (2.34 eV and $3.21 \mathrm{eV}$ respectively) is less than in $\mathrm{SiO}_{2}$ case (4.82 eV for the $\mathrm{Si}-\mathrm{O}$ bond energy [9]).

Electrical reports are preferably focussed on doping of the silicon rich carbide material [10], and of nanocrystals [11-14], sometimes inserted in a heterojunction structure 
[15]. Some information exists on the electrical properties of unannealed, hydrogenated microcrystalline $\mathrm{SiC}$ [16]. However, little attention has been paid to the undoped $\mathrm{Si} / \mathrm{SiC}$ system. In fact, in the framework of a photovoltaic thin film device, the low recombination requirements are probably better fulfilled with an intrinsic material, with the needed electric field guaranteed by separate thin $\mathrm{p}$ - and $\mathrm{n}$ layers, in analogy to the case of a-Si:H p-i-n solar cells. This stresses the importance of an investigation on transport properties of the intrinsic $\mathrm{Si} / \mathrm{SiC}$ system.

The study of the electrical behaviour of the $\mathrm{Si} / \mathrm{SiC}$ system raises different issues with respect to the $\mathrm{Si} / \mathrm{SiO}_{2}$ case. In that case, due to the efficient phase separation and the very good insulating properties of the matrix, carrier transport can safely be ascribed to the silicon nanoparticles subsystem, either the nanodots [14] or the disordered nanodot shell $[\mathbf{1 7}, \mathbf{1 8}]$. Rather sharp variation of transport properties was in fact observed as a function of composition, as the silicon concentration reaches a value compatible with percolation through nanoparticles [19], which allows us to draw conclusions on the origin of transport phenomena in that case. In the case of the $\mathrm{Si} / \mathrm{SiC}$ system, the analysis of the electrical behaviour of the sample is complicated by the not negligible contribution coming from the $\mathrm{SiC}$ matrix, which shorts the conduction through possible barriers between the nanoparticles, the situation being temperature dependent.

To this purpose, knowledge of the structural composition of the sample ( $\mathrm{Si}$ to $\mathrm{SiC}$ relative volumes; residual amorphous $\mathrm{Si}$ and $\mathrm{SiC}$ fractions) is an important basis to the understanding of the electrical properties [20]. A powerful method to monitor the phase separation of the SRC-SiC system is to study their optical properties by extracting refractive index - extinction coefficient (n-k) spectra of the component materials [21] and associate those to suitable computer simulation [22] based on the effective medium approximation (EMA) [23]. A correlation with electrical properties then allows us to improve the understanding of the properties of the material.

In this paper, the multilayer superlattices (SL's) are fabricated by PECVD followed by thermal annealing. The optical properties are determined by Reflection and Transmission spectroscopy (R\&T), associated to computer simulation performed by the code Optical [22]. It is shown that the thermally activated electrical behavior of SL samples is correlated with the microscopic structure as determined by the composition obtained from the effective medium approximation (EMA) [23].

\section{Experimental}

Four SRC/SiC Sl's were fabricated by PECVD both on quartz and on oxidized c-Si substrate. The varying parameters were the SRC composition and the SiC thickness. These samples were labelled according to the form SLx-t, where $\mathrm{x}$ is the Si atomic content in the SRC, ranging between 0.55 and 0.75 , and $\mathrm{t}$ is the $\mathrm{SiC}$ thickness, either 3 or $5 \mathrm{~nm}$. In all cases the SL's were made up of 30 $\mathrm{SRC} / \mathrm{SiC}$ bilayers starting and ending with a stoichiometric SiC layer.The SRC thickness was kept constant and equal to $3 \mathrm{~nm}$. In order to prevent surface oxidation during annealing a $20 \mathrm{~nm}$ thick a-Si:H layer was deposited on the top of each multilayer. $\mathrm{SiC}$ and $\mathrm{Si}$ test single layers were also produced.

PECVD was carried out on substrates heated at 350 ${ }^{\circ} \mathrm{C}$, with plasma frequency equal to $13.56 \mathrm{MHz}$ and power $4 \mathrm{~W} / \mathrm{cm}^{2}$, at 0.95 mbar chamber pressure, using $\mathrm{SiH}_{4}(6.0$ purity), $\mathrm{CH}_{4}$ (5.5 purity) and $\mathrm{H}_{2}(6.0$ purity) as gas precursors. The different SRC compositions were obtained by varying the $\mathrm{SiH}_{4}$ flow rate between $1.6 \mathrm{sccm}$ and 11.4 sccm, keeping $\mathrm{CH}_{4}$ and $\mathrm{H}_{2}$ flow rates equal to $70 \mathrm{sccm}$ and $10 \mathrm{sccm}$, respectively. The resulting $\mathrm{H}_{2}$ dilution of the gas mixtures was between $11 \%$ and $12 \%$.

All samples were annealed in a resistance furnace at $1100^{\circ} \mathrm{C}$ for 30 minutes in fluent $\mathrm{N}_{2}: \mathrm{O}_{2}, 10: 1$. A $4 \mathrm{~h}$ preannealing at $600{ }^{\circ} \mathrm{C}$ was intended to eliminate hydrogen from the material. The annealing was followed by a sequence of etching steps: oxide etching, Si etching and surface cleaning. The $\mathrm{SiO}_{2}$ resulting from the oxidation of the Si top layer was removed in $\mathrm{HF}: \mathrm{H}_{2} \mathrm{O}, 1: 10$ for $60-120$ s (VLSI grade $\mathrm{HF}, 49 \%$, by $\mathrm{KMG}$ ). Any residual $\mathrm{Si}$ is removed from the top of ML's with a 60 s etching at $40{ }^{\circ} \mathrm{C}$ in $2 \%$ tetra methyl ammonium hydroxide (TMAH, semiconductor grade, purchased from Aldrich) solution. The SL's worked as etch-stop. The final sample thickness values are reported in Table 1.

$\mathrm{H}$ effusion and $\mathrm{SiC}$ crystallization were checked by Fourier transform infrared spectroscopy (FTIR). A Thermo Nicolet 5700 spectrometer was used for spectra acquisition. The computation of absorption spectra was

Table 1. $\mathrm{x}=\mathrm{Si} /(\mathrm{Si}+\mathrm{C})$ ratio in the $\mathrm{SRC}$ in the SL's, $\mathrm{Si}$ and $\mathrm{SiC}$ Nominal Volume Fraction after $1100{ }^{\circ} \mathrm{C}$ annealing, computed by considering the shrinkage of the $\mathrm{Si}$ and $\mathrm{SiC}$ components; optically detected $\mathrm{SiC}$ volume fraction (the complement to $100 \%$ is $\mathrm{Si} \%$ ), amorphous and crystallized $\mathrm{Si}$ fraction and total layer thickness; activation energy and exponential prefactor of the conductance as a function of inverse temperature, determined by lateral electrical measurements.

\begin{tabular}{lccccccccc}
\hline & \multicolumn{3}{c}{ Theoretical } & \multicolumn{3}{c}{ Optical measurements } & \multicolumn{3}{c}{ Electrical measurements } \\
\cline { 2 - 10 } Sample & $\mathrm{x}$ & $\mathrm{V}_{\mathrm{Si}}$ & $\mathrm{V}_{\mathrm{SiC}}$ & $\begin{array}{c}\mathrm{SiC} \\
\%\end{array}$ & $\begin{array}{c}\mathrm{a}-\mathrm{Si} \\
\%\end{array}$ & $\begin{array}{c}\mu \mathrm{c}-\mathrm{Si} \\
\%\end{array}$ & $\begin{array}{c}\mathrm{d} \\
(\mathrm{nm})\end{array}$ & $\begin{array}{c}\mathrm{E}_{\mathrm{a}} \\
(\mathrm{eV})\end{array}$ & $\begin{array}{c}\sigma_{0} \\
(\mathrm{~S} / \mathrm{cm})\end{array}$ \\
\hline$\mu \mathrm{c}-\mathrm{Si}-10$ & - & 100 & 0 & 0 & 0 & 100 & 128 & $0.38-$ & 63 \\
& & & & & & & & 0.49 & \\
$\mu \mathrm{c}-\mathrm{Si} 30$ & - & 100 & 0 & 0 & 0 & 100 & 130 & 0.38 & 93 \\
$\mathrm{SL} 75-3$ & 0.75 & 44 & 56 & 55 & 47 & 53 & 134 & 0.21 & 0.097 \\
$\mathrm{SL}$ 65-3 & 0.65 & 31 & 69 & 62 & 58 & 42 & 132 & 0.20 & 0.083 \\
$\mathrm{SL}$ 55-3 & 0.55 & 13 & 87 & 78 & 82 & 18 & 131 & 0.17 & 0.023 \\
$\mathrm{SL}$ 65-5 & 0.65 & 23 & 77 & 70 & 77 & 23 & 159 & 0.19 & 0.020 \\
$\mu \mathrm{c}-\mathrm{SiC}$ & - & 0 & 100 & 100 & - & - & 90 & 0.17 & 0.011 \\
\hline
\end{tabular}


done taking into account substrate, roughness, and baseline correction, and normalization for the sample thickness.

The composition of test single layers was determined by $3.5 \mathrm{MeV}$ He Rutherford Backscattering (RBS) analysis, while the carbon ratio $1-\mathrm{x}=[\mathrm{C}] /([\mathrm{Si}]+[\mathrm{C}])$ was separately checked by X-ray microanalysis, [24] for details. The hydrogen content was determined using Elastic Recoil Detection Analysis (ERDA).

R\&T spectra were measured using an Avantes UV-Vis fiber optics spectrophotometer. All R\&T measurements reported in this paper were elaborated by the code OPTICAL [22], which is based on multilayer approach combined with the Bruggemann Effective Medium Approximation, associated to $\chi^{2}$ minimization of the computed to experimental data.

The lateral conductance as a function of temperature was measured on multilayers deposited on oxidized $\mathrm{Si}$ using parallel plane silver contacts spaced $1 \mathrm{~mm}$. A two terminal configuration was used in a vacuum cryostat. The temperature was varied in the range $27-100{ }^{\circ} \mathrm{C}$. The ohmicity of the contacts was checked in the range $30 \mathrm{~V} /+30 \mathrm{~V}$. Due to the high resistance of the layers, the contact resistance is assumed to be negligible [25].

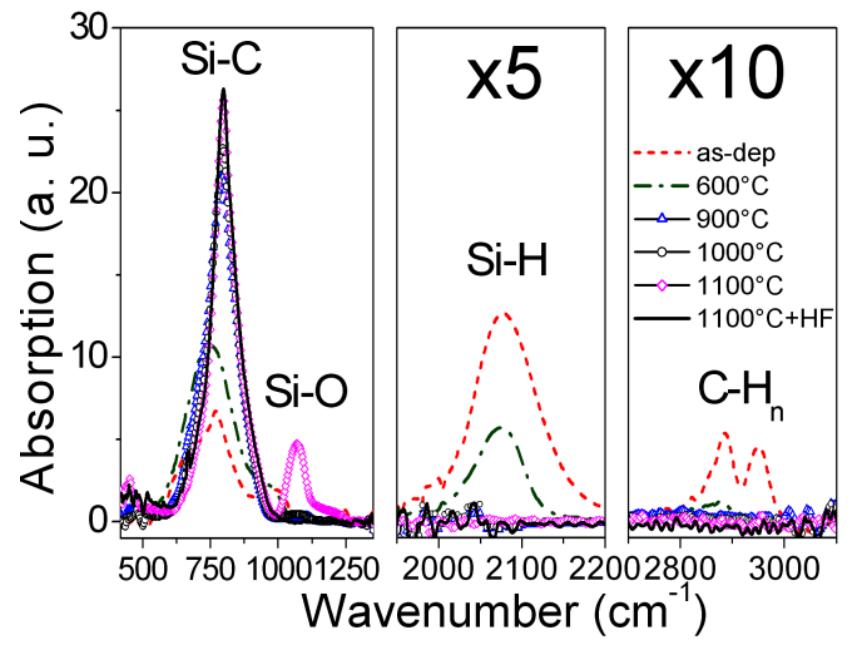

Fig. 1. Fourier transform infrared spectra of SL 75-3, after thickness normalization and baseline subtraction.

\section{Results and discussion}

\section{Nanodot formation}

The formation of nanodots in this set of samples was evidenced by TEM diffraction and reported [20]. TEM diffraction also shows that the $\mathrm{SiC}$ crystallization occurs in the 3C-SiC polytype. Additional information on $\mathrm{SiC}$ crystallization comes from FTIR measurements, reported in Fig. 1 after thickness normalization and baseline subtraction. In the figure, the relevant regions of the absorption spectra are shown. The absorption band associated to the $S i-C$ stretching vibration $\left(780 \mathrm{~cm}^{-1}\right)$ increases upon annealing and the shape changes from gaussian to lorentzian, indicating $\mathrm{SiC}$ crystallization. The $\mathrm{Si}-H$ stretching mode $\left(2050 \mathrm{~cm}^{-1}\right)$ and the $C-H_{n}$ stretching mode (2900 $\mathrm{cm}^{-1}$, very weak signal) absorption bands decrease after annealing, indicating the hydrogen release. The $1063 \mathrm{~cm}^{-1}$ band ( $\mathrm{Si}-\mathrm{O}$ stretch, after $1100^{\circ} \mathrm{C}$ treatment) is related to surface oxidation [26].

\section{Sample composition}

The composition of reference single-layer samples ( $\mathrm{Si}$, $\mathrm{SiC}, \mathrm{SRC}$ of various compositions) was determined by RBS and ERDA as described in the experimental. Given a $\mathrm{SRC}$ of composition $\mathrm{Si}_{\mathrm{x}} \mathrm{C}_{1-\mathrm{x}}$, under the hypothesis of complete separation into $\mathrm{Si}$ and $\mathrm{SiC}$, the relative volume composition of $\mathrm{Si}$ and $\mathrm{SiC}$ depends on density and molecular weight. As an example, in an SRC with 50\% excess silicon, the silicon volume fraction $\mathrm{V}_{\mathrm{Si}}$ is as high as $65 \%$, because of the higher density but lower average atomic weight of $\mathrm{SiC}$ with respect to $\mathrm{Si}$. A general formula for the Nominal Volume Fraction $V_{i}$ of a component $i$ for a silicon rich material completely separated into silicon and the silicon alloy(s), such as for instance also silicon rich oxides, silicon rich nitrides, silicon rich oxinitrides, is given by:

$$
V_{i}=\frac{E_{i}\left(m_{0} r_{i}+m_{i}\right)}{\rho_{i}} \cdot \frac{1}{\sum_{i} \frac{E_{i}\left(m_{0} r_{i}+m_{i}\right)}{\rho_{i}}}
$$

where $i=0$ refers to silicon and higher numbers refer to the different involved "molecules" (or better, formula units), $\mathrm{E}_{\mathrm{i}}$ is the atomic concentration of the element ( $\mathrm{Si}, \mathrm{C}, \mathrm{O}$, or $\mathrm{N}), \rho_{\mathrm{i}}$ and $\mathrm{m}_{\mathrm{i}}$ are the density and molecular mass of $\mathrm{Si}$, $\mathrm{SiC}, \mathrm{SiO}_{2}$, and $\mathrm{Si}_{3} \mathrm{~N}_{4}, \mathrm{r}_{0}$ is zero and $\mathrm{r}_{\mathrm{i}}$ (for $\mathrm{i} \neq 0$ ) is the $\mathrm{Si}$ to- $\mathrm{E}_{\mathrm{i}}$ ratio in the $\mathrm{i}$-molecule(s) respectively $(=1$ for $\mathrm{SiC})$. In the case of an $\mathrm{SRC}$ of composition $\mathrm{Si}_{\mathrm{x}} \mathrm{C}_{1-\mathrm{x}}$, then $\mathrm{E}_{0}=\mathrm{x}$ and $\mathrm{E}_{1}=1-\mathrm{x}$.

The $\mathrm{V}$ is important as some quantities are related to the volume occupied by the compound and not to the atomic concentration. For instance, in the optical simulation, the SiC EMA component within the SRC is related to the volume occupied by $\mathrm{SiC}$ and not to the concentration of $\mathrm{SiC}$ molecules. Also, the total volume occupied by ncSi under complete phase separation is more linked to the $\mathrm{V}_{\mathrm{Si}}$ than on the $\mathrm{Si}$ excess in the sample, which is important in the design of actual devices.

In a SL material composed by $\mathrm{SiC}$ barrier layers and SRC well layers with certain silicon Nominal Volume Fraction $\mathrm{V}_{\mathrm{SiW}}$ as defined in equation (1), the overall $\mathrm{V}_{\mathrm{Si}}$ is given by:

$$
V_{S i}=V_{S i, W} \cdot \frac{d_{W}}{d_{W}+d_{B}}
$$

where $d_{W}$ and $d_{B}$ are the thicknesses of the well and the barrier respectively. This quantity is relevant when simulating the SL's using a single EMA superlayer in which the components reflect the overall $\mathrm{Si}$ and $\mathrm{SiC}$ volume fractions.

\section{Simulation of the R\&T spectra}

After annealing, the SiC-SRC superlattices undergo the 
following processes: hydrogen evolution after the $600^{\circ} \mathrm{C}$ annealing step, which is needed to prevent cracking of the films upon high temperature annealing; partial or complete crystallization of the $\mathrm{SiC}$ matrix; partial or complete separation and crystallization of the $\mathrm{Si}$ component [20]. To follow the structural evolution of the samples upon annealing by means of optical simulation, a database is needed for the n-k functions of the component materials. Fig. 2 reports the $n-k$ functions of the materials involved in the optical simulation. In particular, for amorphous Si we used the n-k files obtained on $600{ }^{\circ} \mathrm{C}$ dehydrogenated samples, while for microcrystallized $\mathrm{SiC}$ we used the $n$-k file obtained with from an $1100{ }^{\circ} \mathrm{C}$ annealed sample. The $n-k$ files were obtained by fitting the R\&T spectra using the Tauc Lorentz approximation as modified by Jellison [27], which was further modified to account for tail absorption (M. Allegrezza, unpublished). For microcrystallized $\mathrm{Si}$ a literature function was used [28]. The a-SiC component was actually never required in the simulations, and is not reported in the figure. This is in agreement with the crystallization of $\mathrm{SiC}$ observed by FTIR.

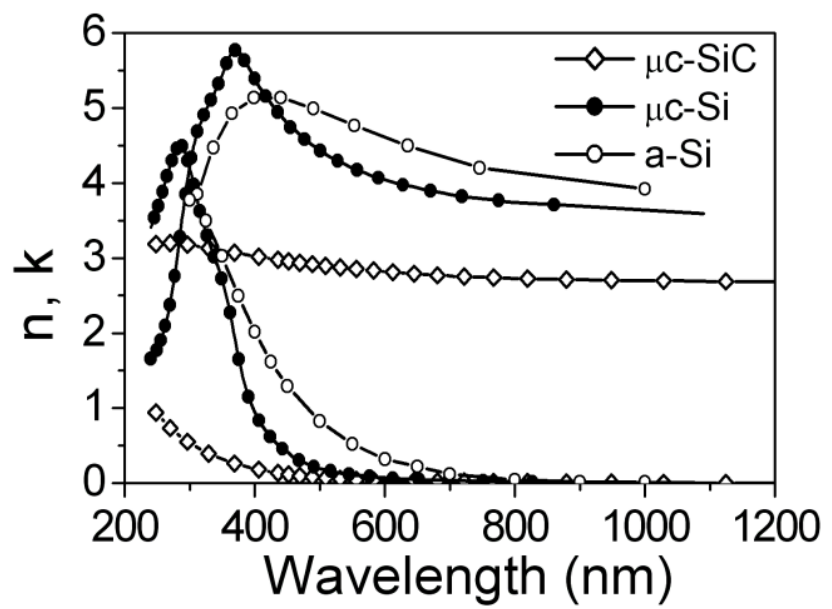

Fig. 2. Spectral n-k for the materials involved in this paper

Such $n-k$ functions were used to simulate the $R \& T$ spectra of the as-deposited (not reported) and annealed SL's. The simulations were carried out by using single superlayers described by an EMA composition of microcrystalline $\mathrm{SiC}$ and microcrystalline or amorphous $\mathrm{Si}$. The results of the simulation are the amorphous-tomicrocrystalline silicon fraction in the EMA, the $\mathrm{SiC}$ fraction, and the layer thickness.

\section{Formation of a surface ternary compound}

From optical simulation, we systematically observed the formation of a surface layer with low refractive index, which is attributed to the formation of a ternary $\mathrm{Si}_{\mathrm{x}} \mathrm{C}_{\mathrm{y}} \mathrm{O}_{\mathrm{z}}$ compound [29], with composition depending on the underlying material. The hypothesis is supported by FTIR observation, that indicate the appearance of a $\mathrm{Si}-\mathrm{O}$ related peak after $1100^{\circ} \mathrm{C}$ annealing (Fig. 1). Such surface layer was observed to affect the electrical measurements. For this reason, we applied a sequence of wet and dry etching to the samples to remove such compound, as briefly described in the experimental. A complete report on the ternary compound and on the procedure needed to remove it will be published soon [26], here we only mention that the electrical measurements reported here are no longer affected by the presence of the surface ternary compound.

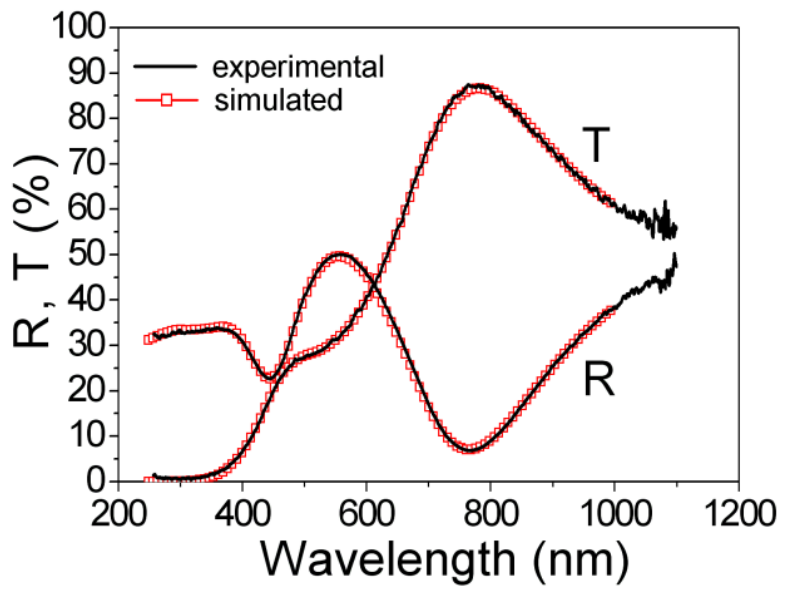

Fig. 3. Experimental and computed R\&T spectra of sample S165-5 after $1100^{\circ} \mathrm{C}$ annealing.

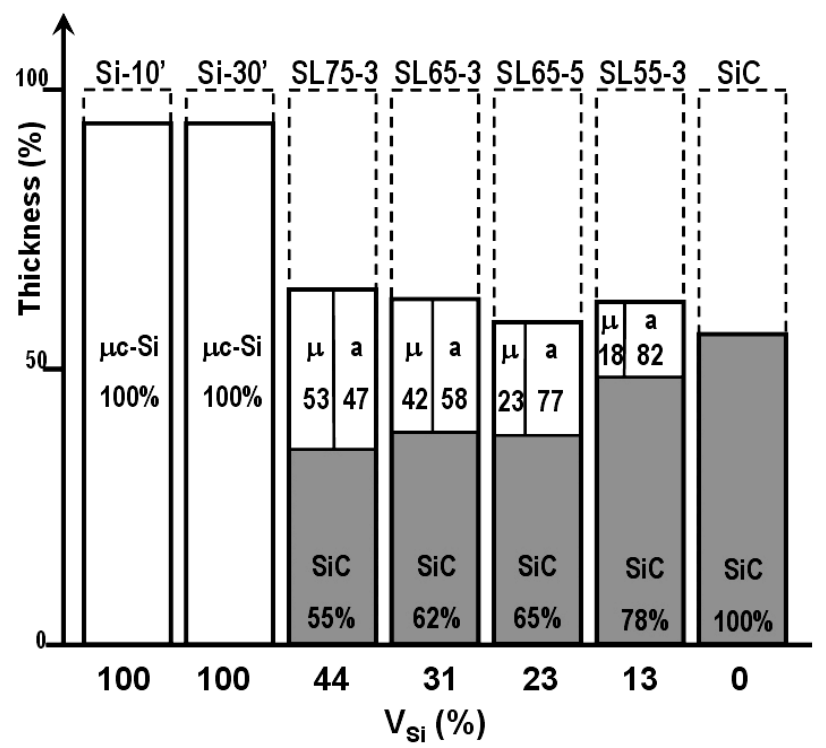

Fig. 4. Sketch illustrating sample thickness variation after annealing, normalized to the as-deposited thickness, and optically determined compositions: $\mathrm{SiC}$ fraction, and $\mu \mathrm{c}-\mathrm{Si}$ (labelled " $\mu$ " in the figure) and a-Si (labelled "a" in the figure) components of the Si fraction (see Table 1).

\section{Results on optical properties}

Fig. 3 shows an example of R\&T spectra and optical simulation of an $1100^{\circ} \mathrm{C}$ annealed SL 65-5. The simulation was obtained with a $159 \mathrm{~nm}$ thick EMA composed by $65 \% \mathrm{SiC}$, and the remaining $\mathrm{Si}$ is composed by $77 \%$ a-Si and $23 \% \mu \mathrm{c}-\mathrm{Si}$. The compositional results obtained on all samples are reported in Table 1. Fig. 4 reports the sketches illustrating the obtained results. It is shown that after annealing, severe shrinkage of the samples occurs, depending on the initial sample 
composition. We attribute the more marked shrinkage for higher initial carbon concentration to the higher hydrogen incorporation in this case. In fact, for thermodynamical reasons, the probability of existence of $\mathrm{Si}-\mathrm{H}$ bonds decreases in favour of the formation of $\mathrm{C}-\mathrm{H}$ bonds as $\mathrm{C}$ concentration increases [30]. The occurrence is illustrated in Fig. 5, that reports the variation of thickness of test $\mathrm{SiC}$ layers and the hydrogen concentration detected by ERDA as a function of sample composition. The composition dependent shrinkage is to be taken into account in the design of an actual device.

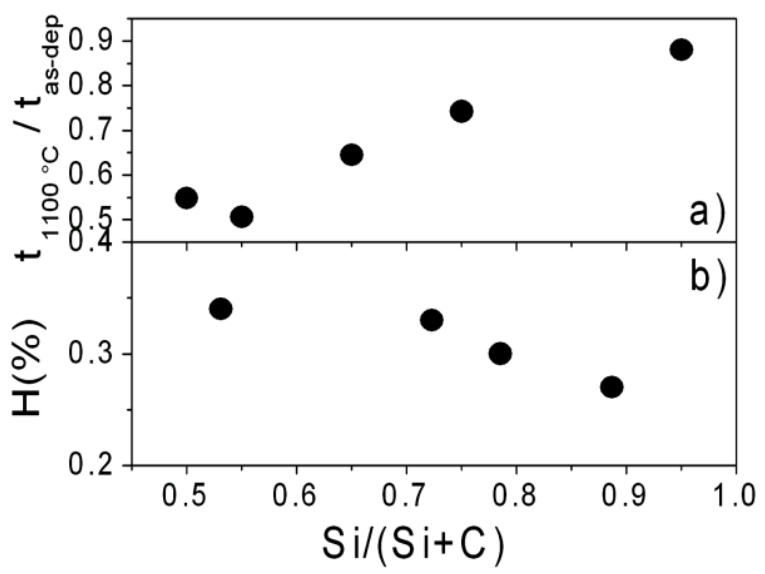

Fig. 5. (a) Thickness variation upon $1100{ }^{\circ} \mathrm{C}$ annealing, and (b) $\mathrm{H}$ concentration determined by ERDA, for single SRC layers as a function of the $\mathrm{Si}$ atomic fraction $\mathrm{x}$.

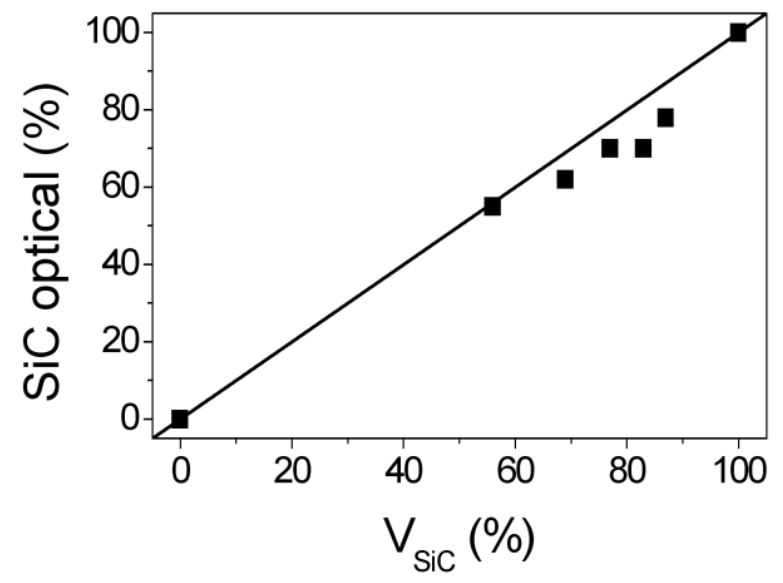

Fig. 6. Optically detected $\mathrm{SiC}$ fraction versus nominal volume fraction for $1100^{\circ} \mathrm{C}$ annealed SL's and reference samples.

To check the validity of optical simulation, in Fig. 6 the optically detected $\mathrm{SiC}$ concentration is plotted against the nominal $\mathrm{V}_{\mathrm{SiC}}$ computed keeping into account the variation of density upon annealing. The observed agreement between the two sets of data confirms the validity of the optically obtained compositional results. The optical results indicate that the $\mu \mathrm{c}-\mathrm{Si}$ fraction in the total $\mathrm{Si}$ component, namely, $[\mu \mathrm{c}-\mathrm{Si}] /([\mu \mathrm{c}-\mathrm{Si}]+[\mathrm{a}-\mathrm{Si}])$, increases for larger initial $\mathrm{V}_{\mathrm{Si}}$ (Fig. 4 and Table 1), i.e. the more silicon in the environment, the higher the probability of crystallization, while small silicon clusters within the $\mathrm{SiC}$ matrix tend to remain amorphous. The result is illustrated in Fig. 7 that reports the $\mu \mathrm{c}-\mathrm{Si}$ fraction versus the $\mathrm{Si}$ atomic concentration in the SRC well layers. In the figure, the thickness of the $\mathrm{SiC}$ barrier, as estimated according to the shrinkage observed in single layers, is also indicated. The figure shows that using a thicker SiC barrier layers reduces the crystallized fraction, thus indicating the efficacy of the $\mathrm{SiC}$ matrix in limiting the growth of the crystallized domains.

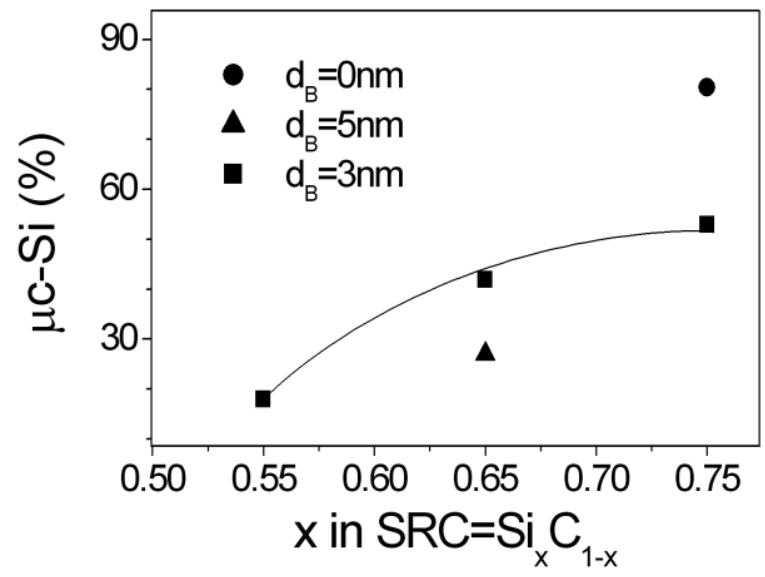

Fig. 7. Optically detected crystallized silicon fraction, as a function of silicon atomic concentration in the well of SL samples. The line connects the data referred to $d_{B}=3 \mathrm{~nm} ; d_{B}=0 \mathrm{~nm}$ indicates a single $S R C$ layer.

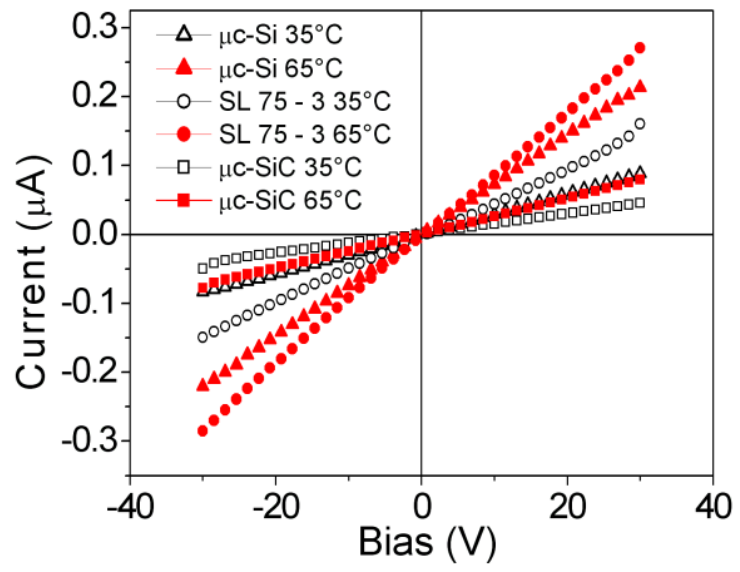

Fig. 8. Room temperature I-V characteristics of SL's and reference samples.

\section{Electrical properties}

All samples were measured using a planar configuration and screen printed Ag contacts followed by no annealing. The ohmicity of the contacts was verified through I-V measurements, reported in Fig 8. The Arrhenius plot of the conductance $\sigma(\mathrm{T})$ of the SL's and of the Si and SiC test single layers is shown in Fig. 9. The figure shows that in all cases the conductivity is thermally activated with a single dependence in the investigated temperature range that can be expressed as: 


$$
\sigma(T)=\sigma_{0} \cdot e^{-E a / k T}
$$

where $\mathrm{T}$ is the absolute temperature and $\mathrm{k}$ is the Boltzmann constant. The pre-exponential factor and the activation energy $E_{a}$ are plotted in Figure 10 as a function of the optically detected $\mathrm{SiC}$ fraction in the samples, where the values 0 and 100 represent microcrystalline silicon and reference barrier respectively, and all other data refer to SL samples. All data are also reported in Table 1 for reference. Fig. 10 shows that both quantities decrease as $\mathrm{SiC} \%$ increases.

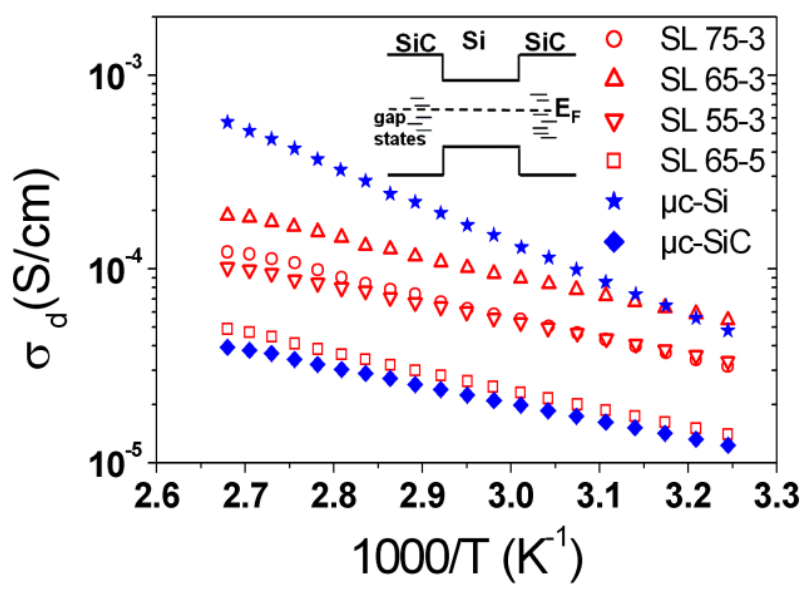

Fig. 9. Conductance as a function of temperature of the SL's and of the two $\mathrm{Si}$ and $\mathrm{SiC}$ single layers.

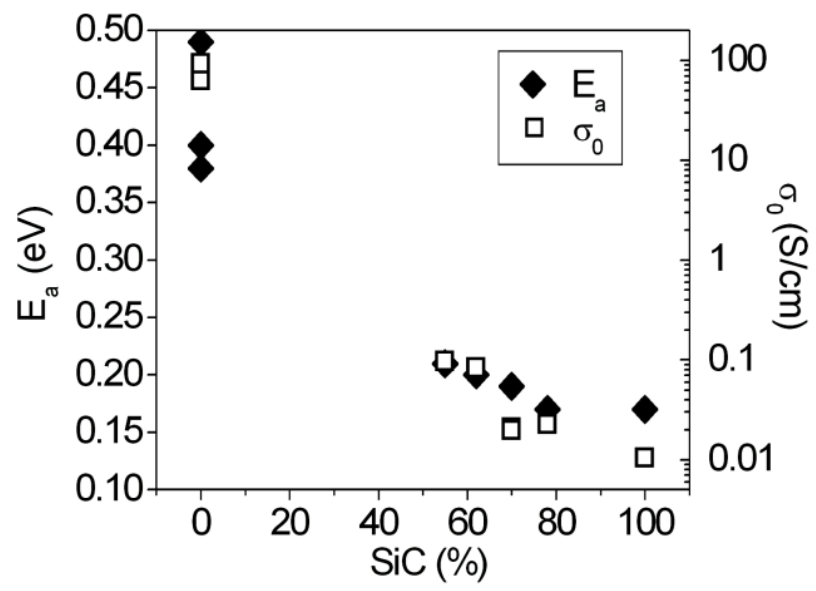

Fig. 10. Activation energy and pre-exponential factor of conductivity Arrhenius plot.

In the case of microcrystallized silicon, $(\mathrm{SiC} \%=0)$, the high value of the pre-exponential factor and an activation energy in the range 0.37 to $0.5 \mathrm{eV}$ indicates, in our undoped samples, an extended states dominated conduction mechanism, as also confirmed by the existence of photoconductivity (data not reported). For increased $\mathrm{SiC}$ fraction concentration, the conductivity pre-exponential factor drops to values in the range $0.01-0.1 \mathrm{~S} / \mathrm{cm}$ while the activation energy decreases to values in the range 0.17 to $0.2 \mathrm{eV}$. This occurrence, associated to the absence of any photoconductivity signal, indicates that the conduction is dominated by transport3hrough gap states associated to defects, and/or tail states hopping, or percolation through potential fluctuations minima. Given the large band gap of $\mathrm{SiC}$, gap states hopping conduction is compatible with the investigated temperature range. The observed conduction parameters of microcrystallized $\mathrm{SiC}$ are also compatible with the presence of an unintended doping impurity, possibly $\mathrm{N}$ or $\mathrm{O}$, which was incorporated either during growth or during the successive annealing steps [31]. A similar was indeed already reported for microcrystalline silicon deposited by PECVD [32].

As already observed while discussing Fig. 4 and Fig. 7, the overall silicon crystallized fraction in the SL's is strictly correlated not only with silicon concentration, but also with the thickness of the barrier layer. In fact (see Fig. 7), a single layer with $\mathrm{x}=0.75$ shows $80 \%$ Si crystallized fraction, against the $50 \%$ of the same material when inserted in the SL.

The increase of the crystallized fraction with $\mathrm{x}$ is related to the dynamics of crystallization that occurs via nucleation and growth of crystalline seeds [33], where nucleation is the limiting step, and decreases for lower silicon volumes [34]. In the case of a SL, the proximity of the interface with $\mathrm{SiC}$ lowers the probability of finding $\mathrm{Si}$ atoms in the neighborhood, limiting the growth of nanocrystals with respect to the single layer case; the dependence on barrier thickness indicates that diffusivity of the involved atoms at $1100^{\circ} \mathrm{C}$ is high enough to cause the process to be sensitive not only to $\mathrm{Si}$ atoms in close proximity, but to a somewhat wider extent. This is also confirmed by TEM observations which show that, in the case of $\mathrm{Si} / \mathrm{SiC}$ system, low barrier and well thickness cause the initial multilayer structure to get smeared out upon $1100^{\circ} \mathrm{C}$ annealing [35]. This result has a dramatic impact on the design of the nc-Si based material in a $\mathrm{Si} / \mathrm{SiC}$ system where spontaneous phase separation is only moderately favoured. It has the side effect that the nanocrystal size is not only governed by the well layer thickness, but also by the silicon fraction, with the unintended presence of a residual amorphous volume fraction.

In other words, a new parameter, (the residual amorphous $\mathrm{Si}$ fraction) beside nanocrystal size and density, arises in the description of the system and needs to be controlled and engineered. The residual amorphous silicon fraction has its impact on electrical and optical properties of the material and must be taken into account in the discussion of the results. Prolonged or more intensive annealing treatments could in principle reduce the residual amorphous fraction; however this solution would not be practical in view of technological applications.

Let's now go back to the discussion of electrical measurements. The activation energy observed for crystallized $\mathrm{SiC}$ is compatible with gap states hopping conduction [36]. Hopping conduction is compatible with the large variety of defects that is known to be present 
even in epitaxial $\mathrm{SiC}[37,38]$. One possible defect in our material is the counterpart in $3 \mathrm{C}-\mathrm{SiC}$ of the $\mathrm{EH} 6 / 7$ in $4 \mathrm{H}-$ $\mathrm{SiC}$ and $6 \mathrm{H}-\mathrm{SiC}[37,38]$, which is located at $0.57 \mathrm{eV}$ below the conduction band and is attributed to a $\mathrm{C}$ vacancy.

Basing on optical results, the SL 55-3 only contains an $18 \%$ microcrystallized silicon out of the $(1-\mathrm{SiC}) \%=$ $22 \%$ total silicon fraction (Table 1). The microcrystallized silicon subdomain is therefore below the percolation threshold [19] and we expect the transport being dominated by the surrounding $\mathrm{SiC}$ matrix, which is actually the observed result (Fig. 9). Similar considerations apply for SL 65-5. The slightly higher conductivity prefactor (Table 1) probably reflects the lower actual SiC volume (with respect to the $100 \%$ used in the determination of $\sigma$ from I (V) measurements) involved in the conduction mechanism. In SL's with higher silicon concentration, the activation energy and conductivity prefactor increase, indicating increased contribution from the crystallized silicon subdomain, although the resulting room temperature conductivity is actually very similar.

In SL $75-3$, we have a 53\% silicon crystallized fraction out of the $(1-\mathrm{SiC}) \%=45 \%$ of the total volume (Table 1), with possibly periodically local higher concentration following the multilayer structure. The conductivity activation energy lower in the case of microcrystallized silicon indicates that a crystallized volume does not form a continuous conduction path within the material. The consequence of the plenty of defects in the $\mathrm{SiC}$ matrix and not in the $\mathrm{Si}$ nanocrystals has actually the counterintuitive consequence that toward low temperature, the contribution of the $\mathrm{SiC}$ matrix dominates, as it is seen at least for the SL 75-3 compared to the $\mu \mathrm{c}-\mathrm{Si}$ sample in the low $\mathrm{T}$ end of the investigated range, see Fig. 9. This occurrence is illustrated in the sketch reported in the inset of Fig. 9. The favoured conduction path then avoids the $\mathrm{Si}$ nanoparticles and proceeds through the $\mathrm{SiC}$. In a device in which the $\mathrm{SiC}$ is the dielectric matrix producing the confinement of the crystallized Si domains, the existence of gap states causes the carriers generated within the nanodots to tunnel into the $\mathrm{SiC}$ matrix, thus preventing the energy collection at the external electrode. For this reason, passivation of the defects is mandatory in view of the application of the material into photovoltaic devices. Indeed, successful experiments of hydrogen plasma passivation of defects in $\mathrm{SiC}$ nanocrystals have already been reported [39].

\section{Conclusion}

In the present work Reflectance \& Transmittance characterization associated to optical simulation is used to determine the evolution of the structure of SiC-SRC superlattices after annealing at $1100^{\circ} \mathrm{C}$. The simulation implies the knowledge of the optical constants of the components of the effective medium approximation. By means of optical simulation it has been observed that the crystallized silicon fraction is correlated to the silicon excess in the well sublayer within the superlattices, as well as on the $\mathrm{SiC}$ barrier thickness. The results shed light on the mechanism of formation and growth of the nanocrystals in $\mathrm{SiC}$ matrix. For low values of the silicon excess, the conductivity of the material is dominated by the $\mathrm{SiC}$ barrier, and is shown to occur via hopping through gap or localized states. Some indication exists on the presence of an unintended dopant impurity that needs to be further investigated. Electrical measurements show that the crystallized silicon subdomain does not form a continuous conduction path, thus confirming the isolated character of nanodots. The importance of passivation required to insert the material in an actual optoelectronic device is emphasised.

\section{Acknowledgements \\ One of the authors (Rimpy Shukla) undertook this work with the support of the ICTP (International Centre for Theoretical Physics) Programme for Training and Research in Italian Laboratories, Trieste, Italy. The research leading to these results has received funding from the European Community's Seventh Framework Programme (FP7/2007-2013) under grant agreement $\mathrm{n}^{\circ}: 245977$ under the project title NASCEnT.}

\section{Reference}

1. Lu, Z.H.; Lockwood, D.J.; Baribeau, J.M.; Nature 1995, 378, 258. DOI: $\underline{10.1038 / 378258 \mathrm{a} 0}$

2. Yu, P.Y.; Cardona, M.; Fundamentals of Semiconductors, Springer Verlag, Berlin, Heidelberg, New York, 1996.

3. Persans, P.D.; Ruppert, A.; Abelès, B.; Journal of Non-Crystalline Solids 1988, 102, 130. DOI : $10.1016 / 0022-3093(88) 90123-8$

4. Lockwood, D.J.; Lu, Z.H.; Baribeau, J.M.; Physical Review Letters 1996, 76,539

DOI : $10.1103 /$ PhysRevLett.76.539

5. Lu, Z.H.; Lockwood, D.J.; Baribeau, J.M.; Solid-State Electronics 1996, 40, 197.

DOI: $\underline{10.1016 / 0038-1101(95) 00245-6}$

6. Zacharias, M.; Heitmann, J.; Scholz, R.; Kahler, U.; Schmidt, M.; Bläsing, J.; Appl. Phys. Lett 2002, 80, 661.

DOI: $10.1063 / 1.1433906$

7. Wan, Z.; Huang, S.; Green, M.A.; Conibeer, G.; Nanoscale Res. Lett. 2011, 6, 129.

DOI: $10.1186 / 1556-276 \mathrm{X}-6-129$

8. Jiang, C.W.; Green, M.A.; J. Appl. Phys. 2006, 99,114902.

DOI: $10.1063 / 1.2203394$

9. Smith, F.W.;Yin, Z.; J. Non-Cryst. Sol. 1991, 137, 871. DOI: $10.1016 / \mathrm{S} 0022-3093(05) 80258-3$

10. Gradmann, R.; Löper, P.; Künle, M.; Rothfelder, M.; Janz, S.; Hermle, M.; Glunz, S.; Phys. Status Solidi C 2011, 8.

DOI: $\underline{10.1002 / \mathrm{pssc} .201000176}$

11. Hao, X.J.;.Cho, E.C.; Flynn, C.; Shen, Y.S.; Park, S.C.; Conibeer, G.; Green, M.A.; Solar Energy Materials \& Solar Cells 2009, 93, 273. DOI: $10.1016 /$ j.solmat.2008.10.017

12. Lechner, R.; Stegner, A.R.; Pereira, R.N.; Dietmueller, R.; Brandt, M.S.; Ebbers, A.; Trocha, M.; Wiggers, H.; Stutzmann, J. Appl. Phys. 2008, 104,053701 .

DOI: $10.1063 / 1.2973399$

13. Hong, S.H.; Kim, Y.S.; Lee, W.; Kim, Y.H.; Song, J.Y.; Jang, J.S.; Park, J.H.; Choi, S.H.; Kim, K.J.; Nanotechnology 2011, 22, 425203. DOI: $10.1088 / 0957-4484 / 22 / 42 / 425203$

14. Cavalcoli, D.; Detto, F.; Rossi, M.; Tomasi, A,; Cavallini, A.; Nanotechnology 2010, 21, 045702.

DOI: $10.1088 / 0957-4484 / 21 / 4 / 045702$

15. Song, D.Y.; Cho, E.C.; Conibeer, G.; Flynn, C.; Huang, Y.D.; Green, M.A.; Solar Energy Materials \& Solar Cells 2008, 92, 474. DOI: $10.1016 /$ j.solmat.2007.11.002

16. Yoshida, N,; Terazawa, S.; Takeuchi, A.; Yoneyama, N.; Morino, T.; Jun, Z.; Natsuhara, H.; Nonomura S.; Phys. Status Solidi C 2010, 7, 790

DOI: $\underline{10.1002 / \mathrm{pssc} .200982732}$

17. Balberg, I.; Dover, Y.; Naides, R.; Conde, J.P.;Chu, V.; Phys. Rev. B 2004, 69, 035203. DOI: $10.1103 /$ PhysRevB.69.035203

18. Azulay, D.; Millo, O.; Savir, E.; Conde, J. P.; Balberg, I.; Phys. Rev. B 2009, 80,245312 
DOI: $10.1103 / \mathrm{PhysRevB} .80 .245312$

19. Balberg, I.; J. Appl. Phys. 2011, 110, 061301. DOI: $10.1063 / 1.3637636$

20. Summonte, C.; Canino, M.; Allegrezza, M.; Bellettato, M.; Desalvo, A.; Mirabella, S.; Terrasi, A.; 26th EPVSEC, 5-9 Sept 2011, Hamburg (D), 361

21. Summonte, C.; Centurioni, E.; Canino, M.; Allegrezza, M.; Desalvo, A.; Terrasi, A.; Mirabella, S.; Di Marco, S.; Di Stefano, M.A.; Miritello, M.; Lo Savio, R.; Simone, F.; Agosta, R.; Phys. Status Solidi C 2011 8, 996-1001.

DOI: $10.1002 /$ pssc. 201000413

22. Centurioni, E.; Appl. Opt. 2005, 44, 7532 . DOI: $\underline{10.1364 / \mathrm{AO} .44 .007532}$

23. Bruggeman, D.A.G.; Ann. Phys. 1935, 24, 636.

24. Summonte, C.; Rizzoli, R.; Bianconi, M.; Desalvo, A.; Iencinella, D.; Giorgis, F.; J. Appl. Phys. 2004, 96, 3987. DOI: $10.1063 / 1.1786679$

25. Song, C.; Rui, Y.; Wang, Q.; Xu, J.; Li, W.; Chen, K.; Zuo, Y.; Wang, C.; J. of Alloys and compounds 2001, 509, 3963. DOI: $\frac{10.1016 / \text { i.jallcom.2010.12.191 }}{\text {. }}$

26. Canino, M.; Summonte, C.; Allegrezza, M.; Shukla, R.; Bellettato, M.; Desalvo, A.; Mancarella, F.; Sanmartin, M.; Terrasi, A.; Löper, P.; Schnabel, M.; Janz, S.; E-MRS 2012 Spring Meeting, Symp. Y, Strasbourg, 2012. Submitted to Material Science and Engineering $B$.

27. Jellison, J.G.E.; Modine, F.A.; Appl. Phys. Lett. 1996, 69, 371. DOI: $10.1063 / 1.118064$

28. Jellison, G.E.; Chisholm, M.F.; Gorbatkin, S.M.; Appl. Phys. Lett. 1993, 62,3348 DOI: $\underline{10.1063 / 1.109067}$

29. Hornetz, B.; Michel, H.J.; Halbritter, J.; J. Mat. Res. 1994, 9, 3088 DOI: $10.1557 / \mathrm{JMR} .1994 .3088$

30. Desalvo, A.; Giorgis, F.; Pirri, C.F.; Tresso, E.; Rava, P.; Galloni, R.; Rizzoli, R.; Summonte, C.; J. Appl. Phys. 1997, 81, 7973. DOI: $10.1063 / 1.365400$

31. Summonte, C; Canino, M.; Allegrezza, M.; Bellettato, M.; Desalvo, A.; Shukla, R.; Crupi, I.; Milita, S.; E-MRS 2012 Spring Meeting, Symp. Y, Strasbourg, 2012
32. Torres, P.; Meier,J.; Flückiger, R.;Kroll, U.; Selvan,J.A.A.; Keppner,H.; Shah,A.; Appl. Phys. Lett. 1996 69, 1373. DOI: $10.1063 / 1.117440$

33. Olson, G.L.; Roth, J.A.; Material Science Reports 1988, 3, 1. DOI: $10.1016 / \mathrm{S} 0920-2307(88) 80005-7$

34. Mirabella, S.; Agosta R.; Franzò G.; Crupi, I.; Miritello, M.; Lo Savio, R.; Di Stefano, M.A.; Di Marco, S.; Simone, F.; Terrasi, A.; J. Appl. Phys. 2009, 106, 103505 . DOI: $10.1063 / 1.3259430$

35. López-Vidrier, J.; Hernández S.; Samà, J.; Canino, M.; Allegrezza, M. Bellettato, M.; Shukla, R.; Schnabel, M.; Löper, P.; López-Conesa, L.; Estradé, S.; Peiró, F.; Janz, S.; Garrido, B.; E-MRS 2012 Spring Meeting, Symp. Y, Strasbourg, 2012. Submitted to Material Science and Engineering $B$.

36. Street, R.A.; Hydrogenated Amorphous Silicon, Cambridge University Press, U.K., 1991, pp. 264.

37. Alfieri, G.; Kimoto, T; Mat Sci Forum 2009, 615-617, 389. DOI: $10.4028 /$ www.scientific.net/MSF.615-617.389

38. Beyer, F.; Hemmingsson, C.; Gällström, A.; Leone, S.; Pedersen, H.; Henry, A.; Janzén, E.; Appl. Phys. Lett. 2011, 98, 152104. DOI: $10.1063 / 1.3579527$

39. Künle, M.; Kaltenbach, T.; Löper, P.; Hartel, A.; Janz, S.; Eibl, O.; Nickel, K.G.; Thin Solid Films 2010 519, 151. DOI: $10.1016 /$ i.tsf.2010.07.085

\section{Advanced Materials Letters}

\section{Publish your article in this journal}

ADVANCED MATERIALS Letters is an international journal published quarterly. The journal is intended to provide top-quality peer-reviewed research papers in the fascinating field of materials science particularly in the area of structure, synthesis and processing, characterization, advanced-state properties, and applications of materials. All articles are indexed on various databases including $\underline{\mathrm{DOAJ}}$ and are available for download for free. The manuscript management system is completely electronic and has fast and fair peer-review process. The journal includes review articles, research articles, notes, letter to editor and short communications.
JOURNAL,

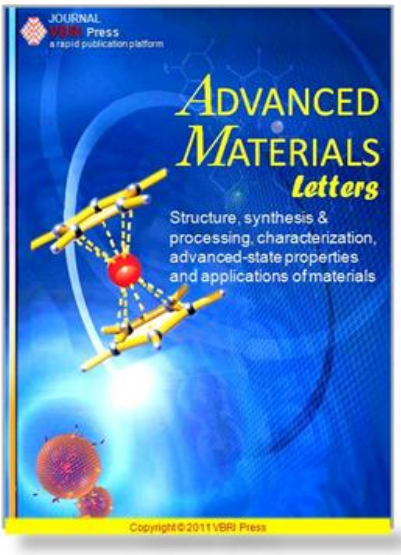

